\section{Greek politics stall research reforms}

The ongoing damage to Greek scientific research is not solely due to austerity measures

(Nature 517, 127-128; 2015).

In my experience as a member of Greece's National Council for Research and Technology from 2010 to 2014, political manipulation and institutional weakness are also contributors.

To address the dire problem of underfunded research, in 2011 the council introduced an open, competitive grant scheme (called Aristeia, or excellence) based on the European Research Council model. It ran for two rounds, during which we had to battle against other governmental forces to maintain its European Union (EU) funding. The scheme now seems to have been abandoned.

The council developed a multiannual plan that year for research and development $(\mathrm{R} \& \mathrm{D})$ to bring Greece closer to EU expenditure targets by 2020. This was stalled and diverted by government. We pressed for the creation of a high-level government committee to oversee $\mathrm{R} \& \mathrm{D}$, and for a research agency similar to the US National Science Foundation. That plan was also lost, diluted by the research law you mention.

The council's experience reflects the wider problems of Greece's government: how it seeks and receives expert advice, the public status of this process and the near-impossibility of rational, stable long-term planning. The shallow and short-term strictures of the 'troika' - the three organizations that act for Greece's creditors - make matters worse. Kevin Featherstone London School of Economics \& Political Science, UK.

k.featherstone@lse.ac.uk

\section{Leave Brazil's Red List alone}

Brazil's government has agreed to review its updated Red List of the country's threatened marine species. This review represents a victory for lobbyists in the fishing industry. It is not based on new biological information.

The list that was issued in

December 2014 by Brazil's environment ministry (through decrees 444 and 445) was the culmination of a six-year process involving 1,300 national and international scientists, overseen by the International Union for Conservation of Nature. It restricts or bans the capture of several commercially valuable fish, such as groupers and sharks.

The fishermen's unions last month questioned the criteria for inclusion and persuaded Helder Barbalho, minister of fisheries and aquaculture, and environment minister Izabella Teixeira to review the list.

A repeal of decree 445 or an amendment of the Annex I list, which regulates the capture of 409 fish species and 66 aquatic invertebrates, would be a serious setback for conservation and for the sustainable management of fisheries in Brazil.

Alexander C. Lees Museu Paraense Emílio Goeldi, Belém, Pará, Brazil. alexanderlees@btopenworld.com

\section{EU research plan may widen gaps}

The success of the European Union (EU) Research and Innovation programme depends on achieving critical mass among member states and optimizing each state's research contribution (see also M. Żylicz Nature 517, 438; 2015). This could be difficult, given the wide variation in each state's willingness to participate and in their investment in research.

Research excellence and competitiveness remain concentrated in just a few geographical areas, despite efforts by the EU to promote homogeneity. It is those regions that make the advances in research and technology, fuelling the imbalance (see K. Schwab (ed.) The Global Competitiveness Report 2013-2014 World

Economic Forum, 2013).

The EU plan to align national research programmes could make matters worse. Closer cooperation between researchers and between states will help to secure research sponsorship and collaboration with scientists outside Europe. But these advantages are more likely to be enjoyed by highperforming countries, further widening the gap from the others. The proposed alignment will also have to struggle with extra bureaucracy and delays (M. Cuijpers et al. Res. Policy 40, 565-575; 2011).

Pier Francesco Moretti National Research Council of Italy,

Brussels, Belgium.

pierfrancesco.moretti@cnr.it

\section{Biodiversity: include freshwater species}

The omission of freshwater species from your biodiversity assessment (Nature 516, $158-161$; 2014) reflects a more general bias towards terrestrial conservation, borne of insufficient knowledge about freshwater ecosystems. The Red List of the International Union for Conservation of Nature, for example, is dominated by freshwater fish species whose population status is unknown.

Integrative conservation measures are particularly important in places where people depend on freshwater resources for subsistence, and where human activities are rapidly changing rivers, lakes and their surrounding landscapes. The highly biodiverse Amazon River basin is an example. In parts of Africa, diminishing supplies of freshwater fish have led to the overexploitation of terrestrial animals (J. S. Brashares et al. Science 306, 1180-1183; 2004)

We need more data for freshwater ecosystems to inform conservation strategies and to integrate them with terrestrial habitats.

Sebastian Heilpern University of Chicago, Illinois, USA.

sheilpern@uchicago.edu

\section{Biodiversity: sharks and rays in peril too}

Your status report on fauna biodiversity (Nature 516, 158-161;2014) overlooks a group that is causing serious concern among conservationists — sharks, rays and chimaeras. These are particularly vulnerable to fishing and by-catch, in part because they mature late and produce few young.

An estimated $24 \%$ of this group, known as chondrichthyan fish, are threatened with extinction under the Red List criteria of the International Union for Conservation of Nature. This exceeds the percentage for birds and is comparable to that for mammals. There are insufficient data to determine status in $47 \%$ of chondrichthyan fish, and models predict that many of these could also be under threat, given their similar life history and morphology to the listed chondrichthyans.

Extinction of ocean fish is hard to verify. There is as yet no documented global extinction of a chondrichthyan, but many populations are locally or regionally extinct (such as sawfishes (Pristidae family); see N. K. Dulvy et al. Aquat. Conserv. http://doi.org/zkc; 2014). Some critically endangered species, including the Pondicherry shark (Carcharhinus hemiodon) in the Indo-West Pacific, have not been recorded in decades and may already be extinct.

Peter M. Kyne Charles Darwin University, Darwin, Australia.

Nicholas J. Bax CSIRO, Australia; and University of Tasmania, Hobart, Australia. Nicholas K. Dulvy Simon Fraser University, Burnaby, Canada. peter.kyne@cdu.edu.au 